\title{
Loneliness, social dislocation and invisibility experienced by older men who are single or living alone: accounting for differences across sexual identity and social context
}

\author{
Paul Willis $^{1 \star}$ (D), Alex Vickery ${ }^{1}$ and Tricia Jessiman ${ }^{2}$ \\ ${ }^{1}$ School for Policy Studies, University of Bristol, Bristol, UK and ${ }^{2}$ Bristol Medical School: Population Health \\ Sciences, University of Bristol, Bristol, UK \\ *Corresponding author. Email: paul.willis@bristol.ac.uk
}

(Accepted 29 June 2020; first published online 27 July 2020)

\begin{abstract}
Across literature on loneliness and ageing, little attention is given to the intersection of ageing, sexuality and masculinities, and how this shapes the social connections of older men. We report findings from a qualitative study of older men's experiences of loneliness and social participation, focusing on perspectives from two groups who are single and/or living alone: men identifying as (a) heterosexual and (b) gay (not bisexual). We present findings generated from semi-structured interviews with 72 men residing in England (65-95 years). We discuss three prominent themes: (a) loneliness, loss and social dislocation; (b) diverging life-events that trigger loneliness; and (c) variations in visibility and exclusion across social settings. Embedded within men's descriptions of loneliness is a running theme of social dislocation that speaks to a wider sense of social separation and estrangement. Unique to gay men's accounts are the ways in which experiences of loneliness and social isolation are compounded by living in heteronormative social environments and their encounters with ageism in gay social settings. Older men's accounts convey anxieties about visibility and anticipated exclusion across social settings shared with other men that vary according to sexual identity and context. We discuss how sexuality and being single and/or living alone impact on older men's social participation as we seek to move beyond a heterocentric understanding of loneliness.
\end{abstract}

Keywords: older men; loneliness; social isolation; masculinities; social connections; social networks; gay; sexuality

\section{Introduction}

Loneliness has been framed as a 'pressing public health issue' by policy makers in the United Kingdom (UK) (HM Government, 2018) and rapidly become a phenomenon of policy, practice and research concern. When accounting for gender-

(C) The Author(s), 2020. Published by Cambridge University Press. This is an Open Access article, distributed under the terms of the Creative Commons Attribution licence (http://creativecommons.org/licenses/by/4.0/), which permits unrestricted re-use, distribution, and reproduction in any medium, provided the original work is properly cited. 
based differences in loneliness trends, women are more likely to report loneliness than men (Office for National Statistics (ONS), 2018). Reasons for this can be partly explained by women's higher likelihood of being unpartnered in later life as well as men's reluctance to speak about, seek help for or self-report loneliness (Vozikaki et al., 2018; Victor et al., 2006). In contrast, a greater percentage of older men in England report moderate to high levels of social isolation (Beach and Bamford, 2013) and research from the UK and the Netherlands indicate how older men without partners report higher levels of loneliness and isolation than women without partners (Davidson et al., 2003; Dykstra and Fokkema, 2007; Milligan et al., 2015). Prior studies of loneliness in later life have neglected to examine how lesbian, gay and bisexual (LGB) older individuals experience loneliness and social isolation (Fish and Weis, 2019), which generates a heterocentric understanding of social connections in older age. This is further evident in contemporary policy making through the lack of recognition of LGB lives and identities in policies seeking to tackle loneliness. For example, the 2020 Loneliness Annual Report issued by the UK government does not make any mention of sexual orientation or LGB identities (HM Government, 2020).

In this paper, we focus on the social participation of older men (identifying as heterosexual and gay) who are single and/or living alone (65-95 years) and we critically examine older men's descriptions and experiences of loneliness across different social contexts. We concentrate on this cohort as, first, an increasing number of adults are living alone in the UK, of whom older adults make up the largest number of 'one-person households' (ONS, 2019), and second, the intersection between masculinities, sexual identity and older age is rarely examined in current approaches to understanding and addressing loneliness. Our aims are twofold: (a) to examine how older men talk about loneliness and position themselves within available discourse on these dimensions, and (b) to identify how differences across sexual identity and social context shape their experiences and self-perceptions. We ask: how do older heterosexual and gay men who are single and/or living alone experience loneliness and maintain social connections with others? We argue that anchored within men's descriptions of loneliness is a running theme of social dislocation that speaks to a profound sense of social separation and distancing from others. Findings are presented from a qualitative study of older men's experiences of loneliness and isolation across seldom-heard groups in England (2016-2019). First, we consider four key streams of literature informing this topic.

\section{Background literature}

There are four streams of literature informing the background terrain of this paper: (a) conceptualising and understanding experiences of loneliness in later life, (b) the social connections and networks of older men, (c) gay men's experiences of loneliness in later life, and (d) belonging, masculinities and later life.

\section{Conceptualising and understanding experiences of loneliness in later life}

While the definition of loneliness varies across the literature, there is a unifying theme of loneliness being a subjective and unpleasant emotional state: an individual 
experiences loneliness when they perceive a discrepancy between the number and/ or quality of relationships that they have, and the number/quality that they would like to have (De Jong-Gierveld, 1987: 120). Loneliness is relational as it hinges on an individual's subjective awareness of what it means to experience meaningful and rewarding relationships with others (Jylhä and Saarenheimo, 2010).

Loneliness is also understood to be multi-dimensional, encompassing emotional, social and existential forms. Emotional loneliness is closely aligned with the loss of meaningful relationships (such as being widowed or separated from partners) and a desire for fulfilling relationships with others (Weiss, 1973; Tiilikainen and Seppänen, 2017). Social loneliness is the perceived absence of engagement with social groups and dissatisfaction with one's social network (Weiss, 1973; De Jong Gierveld and Tilburg, 2006). Perlman and Peplau (1981: 32) point to the discrepancy between 'one's desired and achieved levels of social relations' as generating feelings of social loneliness. Alternatively, Cacioppo et al. (2015) classify emotional and social loneliness as 'intimate' and 'relational', respectively, and note a third type, 'collective loneliness', in reference to the felt absence of contact with wider social groups and affiliations. The concept of 'existential loneliness' captures the sense of social separation, alienation and disconnection older people experience from social life around them (Bolmsjö et al., 2018). According to Mijuskovic (1979), loneliness is the basic structure of consciousness, as such, it is a category of existence and inevitable part of the human condition. Ettema et al. (2010: 151) situate existential loneliness as an ontological state where 'one is always and fundamentally separated from others'. This experience is deeply subjective and as such it is a slippery concept to operationalise in empirical research (Ettema et al., 2010).

In parallel, social isolation is defined as an objective or factual state that infers absence of contact with other people (Beach and Bamford, 2013; Jopling, 2015) or separation from others (Ettema et al., 2010). Living alone is one criterion by which it is measured (Gale et al., 2018). Periods of isolation can generate subjective experiences of solitude or loneliness; the former being characterised as constructive while the latter is recognised as disruptive to one's social and emotional wellbeing (Ettema et al., 2010). While isolation can trigger feelings of loneliness (Buffel et al., 2015), social isolation is not synonymous with loneliness and loneliness can be experienced irrespective of the size of an individual's social network (Durcan and Bell, 2015).

\section{The social connections and networks of older men}

The social constructs of gender and sexuality are important dimensions shaping the ways in which older adults experience loneliness and social isolation. Our discussion of the intersection between gender, sexuality and older age is informed by an intersectional approach, as first discussed by Crenshaw (1991) and, in the context of ageing and sexuality, by Hulko (2016) and King et al. (2019). Intersectionality provides a sociological lens for understanding the complex ways in which social identity categories coalesce and compound experiences of social disadvantage and inequality. While there is a growing body of literature on men, masculinities and loneliness, less attention has been given to gay, queer and bisexual men's experiences. Often sexuality is not recognised as an integral social dimension 
for developing approaches to addressing loneliness in later life. Furthermore, it is often unclear within research literature on older adults, loneliness and gender-based differences if studies are focusing on heterosexual participants solely as sexuality is not discussed as a sample characteristic. This absence generates a heterocentric understanding of loneliness that does not grapple with differences across gender and sexual identity.

Research from the UK and the Netherlands indicates that older heterosexual men are more likely to be reliant on their (female) partner for maintaining their social life and nourishing social connections with adult children, family and friends (Bennett et al., 2003; Davidson, 2004; Dykstra and Fokkema, 2007). Women, including partners and daughters, play a key role in the development and maintenance of the social networks of heterosexual men. This resonates with trends identified in Australia in which men in different-gender relationships look to spouses and female partners for maintaining social ties with family and friends as a form of 'kinship work' (Franklin et al., 2019). Divorce and widowhood are significant life-events that impact on the size of men's social networks. Divorced men are more likely to experience emotional loneliness than divorced women in the Netherlands (Dykstra and Fokkema, 2007), and older men in Australia are less likely to maintain levels of social engagement in widowhood, including contact with children (Isherwood et al., 2012). A more recent study of Australian men (70+ years) found that men living alone experienced greater psychological distress and worse physical health than men living with a spouse/partner (Byles et al., 2016).

From Davidson's (2004) UK findings, never-married men were least likely to be unhappy with their lone status in comparison to men in other relationship groups. This resonates with Yetter's (2010) findings from the United States of America (USA) that living alone can be a positive experience for some older men. It also highlights the heterogeneity of the lives of older men who are living alone, and as Leontowitsch et al. (2019) argue, counteracts dominant narratives that frame men in this group as being at risk and vulnerable to social isolation. While the above scholarship illuminates important trends for older heterosexual men, there is limited engagement with the implications for older gay men experiencing loneliness.

\section{Gay men's experiences of loneliness in later life}

Literature on the experience of loneliness and social isolation amongst older people who identify as LGB rarely distinguishes findings specific to gay men only and often bunches men's and women's experiences together. Several studies of older LGB adults suggest that this group are at greater risk of loneliness than their heterosexual peers, which may be explained in part by their greater experiences of identified risk factors for loneliness, including being single, living alone and having less-frequent contact with biological family (Guasp, 2011; Fokkema and Kuyper, 2009; Hughes, 2016). Based on survey data from the Netherlands, Fokkema and Kuyper (2009) found that older LGB individuals were lonelier than their heterosexual peers, and that this difference was greater for men. Survey research from Great Britain (Guasp, 2011) and other economically advantaged nations (Higgins et al., 2011; Lyons et al., 2012; Brennan-Ing et al., 2014) suggest that older LGB people 
are more likely to live alone than heterosexual peers. Partner status is predicated as a protective factor against loneliness. USA survey results indicate that older LGB adults living alone or with others report greater loneliness than those living with a partner (Kim and Fredriksen-Goldsen, 2016).

There is less evidence that older LGB people as a population are more at risk of social isolation. Arguably, older LGB people have weaker ties to biological kin than heterosexual older adults and are more likely to look to non-related care-givers for instrumental and emotional support, such as friends (Croghan et al., 2014; Brennan-Ing et al., 2014). The term 'chosen families' has been applied to lesbian's and gay men's lives to denote the ways in which individuals form strong ties with friends as alternative kinship bonds to biological family, looking to friendships for social support (Weston, 1997). A UK study of the social networks of older LGB (and transgender) adults found that they had weaker familial networks, but also had more friends and community contacts (Green, 2016). Findings vary on the prominence of 'chosen families' within the social networks of older LGB adults in the UK (Heaphy et al., 2004) and Australia (Hughes, 2016). Oswald and Roulston (2018) explored the social lives of older gay men in New York City and proposed a model of complex intimacy, reporting how the ageing body combined with being a gay man in the 20th century resulted in enduring losses that older gay men seek to manage by seeking out gay environments and connecting with younger gay men. Pereira et al. (2017) identified these dimensions in their participants' responses, which included different types of resources that older gay and bisexual men in Portugal used to cope with ageing and make it more successful.

The psychological concept of minority stress is frequently turned to as an explanatory theory for LGB adults' increased risk of loneliness in later life. First defined by Meyer (2003) in the USA, minority stress is the excess stress to which LGB individuals are routinely exposed to across heteronormative social environments. This can occur through stressful events such as experiences of hostility and discrimination (e.g. homophobia), the anticipation of hostile responses from others and the internalising of homonegative beliefs (Meyer, 2003). Meyer argued that LGB individuals learn to anticipate stigmatising experiences based on previous experiences of discrimination or exclusion coupled with the impact of living in a negative social environment. Anticipated stigma is also discussed in the context of how older men manage the stigma of living with HIV in later life; this is another health factor associated with loneliness (Grov et al., 2010; Emlet et al., 2013).

For older gay men experiencing young adulthood in the 1950s and 1960s, their life-stories are marked by periods of criminalisation of sex between men (before partial decriminalisation in 1967 in England and Wales) and medical pathologisation through the diagnosis and treatment of homosexuality as mental disorder (see Willis et al., 2018). The concept of heteronormativity brings attention to the social configuration of heterosexuality as a normative marker of socio-sexual relationships and the unique stressors this generates for LGB individuals whose relationships and identities do not fit this normative mould. As described by Kitzinger (2005: 478), heteronormativity captures the 'myriad ways in which heterosexuality is produced as a natural, unproblematic, taken-for-granted, ordinary phenomenon'. This constant reproduction can render older LGB adults' relationships invisible to service providers or inform assumptions that all older clients are heterosexual (Almack, 2019). 


\section{Belonging, masculinities and later life}

Writing from an Australian context, Franklin et al. (2019) have argued the need to understand loneliness from a sociological perspective and put forward the notion of 'belongingness' as a lens for understanding how men experience loneliness differently from women in contemporary society. The gendered environments and cultures within which men have traditionally formed close ties and bonds, inclusive of work and public spaces, have undergone significant social and economic change over the last century. This is due to neoliberal trends in the organisation of work and public life, and associated patterns of increasing individualisation. The social bonds men have previously maintained with other men across organisations and institutions have become fragmented or diminished (Franklin et al., 2019).

Belongingness in later life is also disrupted by other social processes associated with old age. Functionalist theories of ageing, such as disengagement theory, posit that withdrawal from social roles and norms is inevitably bound with growing older (Markson, 1975). In contrast, critical perspectives on ageing point to a cultural process of 'othering' experienced by individuals in later life where 'old age is represented as another country' and defined as a separate social void of decline and detachment (Higgs and Gilleard, 2020). The othering of old age generates further social voids between younger and older adults and between older people. Within scholarship on men and old age, social gerontologists seek to examine how older men are positioned as 'the other' and attributed lower social status in later life when compared to the hegemonic ideal of masculinity (Calasanti, 2004). Dominant images of disengagement accompany older men's lives, whether through entering retirement, experiencing changes to family roles or being positioned as the antithesis to male youth (Hearn, 1995). Connell's (1995) sociological work on gender relations has been key to this body of literature.

Connell's writing on masculinity, or the now preferred term of masculinities, points to ways in which normative ideas about 'being a man' within and throughout all aspects of life are culturally reproduced and enacted. Through Connell's (1995: 71) sociological lens, gender is a social process (or 'configuring practice') through which social life is organised and 'not a fixed set of biological determinants'. Masculinities are enacted and embodied within a wider social system of gender relations. The notion of hegemonic masculinity captures dominant, cultural ideals about masculine behaviour and identity linked with the institutional power conferred to (some) men in patriarchal social structures. Connell and Messerschmidt (2005: 836) propose that a relational perspective is integral to understanding how hegemonic masculinities are enacted as masculinities represent 'configurations of practice' that can differ 'according to the gender relations in a particular social setting'.

Within a social hierarchy of masculinities, both 'gayness' and 'old age' represent subordinate masculine identities (Slevin and Linneman, 2010). Old age is habitually associated with a loss of strength, autonomy, and physical and mental resiliencies (Bennett, 2007), all of which can conflict with standards of hegemonic masculinity. Older men embody subordinate masculinities through cultural invisibility and associations with ageing, declining bodies. 'Ageing overshadows gender' and men in later life can be homogenised as 'older' (Thompson, 2006: 633). For older gay men, the ageing body can represent an embodied site of struggle and stigma as 
'gay male culture puts a very specific body on a pedestal' (Slevin and Linneman, 2010: 503), namely youthful, virile and athletic. Slevin and Linneman (2010) suggest that older gay men struggle to live up to hegemonic masculine ideals while seeking to hold back the physical and sexual decline associated with ageing.

This struggle also manifests in older men's experiences of gay commercial and social environments where they encounter a lack of age-friendly social spaces and report feeling excluded from a social world that places higher value on youthful identities and socio-sexual bonds (Jones and Pugh, 2005). The stereotype of 'accelerated ageing' in gay male cultures infers the subjective experience of 'becoming' middle-aged and older earlier in life in comparison to heterosexual men, although evidence to support this notion is contested (Bennett and Thompson, 2008). These expressions of ageism do not inhibit middle-aged and older gay men from enacting what Simpson (2012) terms as 'ageing capital' - the accumulation of knowledge, self-awareness and strength in recognising age-based boundaries and norms operating within gay social spaces, and capacity to challenge homophobic and ageist attitudes present in heterocentric spaces. Having laid out the empirical and theoretical roots of this paper, we now outline the study design before presenting key thematic findings.

\section{Research design and methods}

The findings we discuss below are from a cross-sectional study of older men's experiences of loneliness, social isolation and participation across seldom heard groups in England (2016-2019). The study was conducted in partnership with Age UK as a voluntary organisation championing the rights of older people. Ethical approval was received from the NHS England Social Care Research Ethics Committee (Ref. 17/ IEC08/0004). One hundred and eleven men (65-95 years) from the following groups took part in semi-structured interviews: men who were single and living alone in urban $(\mathrm{N}=22)$ and rural areas $(\mathrm{N}=22)$; men who identified as gay and were single or living alone $(\mathrm{N}=21)$; men who were caring for a significant other $(\mathrm{N}=25)$; and men with hearing loss $(\mathrm{N}=21)$. In this paper, we focus on the accounts of 72 older men who were single and/or living alone at the time of interview and residing in urban and rural settings. This includes both heterosexual and gay-identifying men (see Table 1).

\section{Sampling and interview methods}

Men were recruited through purposive sampling and we relied on the assistance of relevant organisations and services targeted at older people, particularly older adults belonging to the groups identified above. We created a recruitment list of public, third-sector and voluntary organisations, as well as social clubs and societies, compromised of mostly older members and based in South-West and West England, and invited key stakeholders from organisations/groups to advertise the study to men $65+$ years who accessed their service or programme. In excess of 200 organisations and groups were contacted. We deployed this method as we sought to learn more about older men's experiences of engaging with and participating in groups (whether run through organisations or community networks).

All men took part in interviews that ran for 1.5-2 hours in duration, typically taking place in participants' homes. Written informed consent was gained prior 
Table 1. Numbers of participants who were single and/or living alone across sub-groups

\begin{tabular}{lccccc}
\hline & & & & Ethnic background \\
\cline { 3 - 6 } & $\begin{array}{c}\text { Number per } \\
\text { Sample group }\end{array}$ & $\begin{array}{c}\text { Age } \\
\text { range }\end{array}$ & $\begin{array}{c}\text { Mean } \\
\text { age }\end{array}$ & $\begin{array}{c}\text { White } \\
\text { British }\end{array}$ & Asian \\
\hline $\begin{array}{l}\text { Men identifying as } \\
\text { heterosexual }\end{array}$ & $51^{1}$ & $65-95$ & 76 & 49 & 2 \\
\begin{tabular}{l} 
Men identifying as gay \\
\hline
\end{tabular} & $21^{2}$ & $65-85$ & 76 & 20 & 2 \\
\hline
\end{tabular}

Notes: $\mathrm{N}=72$. 1 . Twenty-eight were widowers. 2. Nineteen identified as single while two additional men had partners but lived alone and were therefore included in the study.

to interview with ongoing consent sought verbally throughout. At completion of interviews, each participant was provided with a list of older people's support services in their local area and offered a $£ 20$ high-street store voucher as a token of appreciation. Participants were asked about the membership of their current social networks and levels of social engagement with network members, their experiences of loneliness and isolation (both in current and earlier life), and their participation in group interventions and social activities. When seeking to initiate discussion about loneliness as a highly sensitive topic, questions from the UCLA three-item loneliness scale (Hughes et al., 2004) were used: 'How often do you feel that you lack companionship?', 'How often do you feel left out?' and 'How often do you feel isolated from others?' Gay male participants were asked additional questions about their experiences of identifying as gay in contemporary society and earlier decades, and their experiences of previous same-sex relationships and contact with gay and LGB groups and networks.

\section{Analysis}

All interviews were recorded and transcribed. The data were categorised across a matrix created in NVivo 11, following the framework approach for qualitative analysis and data management (Gale et al., 2013). Three members of the team read a small sample of transcripts to develop the initial coding framework which incorporated a priori categories identified in the literature, topics from the interview schedule and categories arising inductively. Once the analytical framework was confirmed it was populated with data charted from the transcripts by two of the authors. Categorical data were thematically analysed using an iterative process of moving between initial coding line-by-line and defining and naming recurrent themes across the data-set (Braun and Clarke, 2006). Three core themes are presented below (Table 2 gives a breakdown of themes and sub-themes). Participants have been allocated numerical codes to protect anonymity.

\section{Key findings}

\section{Loneliness, loss and social dislocation}

Elements of social and emotional/intimate loneliness were present across men's descriptions of loneliness. Some men described lacking a close companion/partner 
Table 2. Outline of core themes and sub-themes

\begin{tabular}{ll}
\hline Core themes & \multicolumn{1}{c}{ Sub-themes } \\
\hline Loneliness, loss and social dislocation & $\begin{array}{l}\text { - Intimate loneliness: widowhood and } \\
\text { bereavement }\end{array}$ \\
& $\begin{array}{l}\text { - Loneliness and living alone } \\
\text { Social dislocation and disconnection } \\
\text { in later life }\end{array}$ \\
\hline $\begin{array}{l}\text { Identifying triggers for loneliness: differences } \\
\text { across social context and sexual identity }\end{array}$ & $\begin{array}{l}\text { Loneliness and isolation in a } \\
\text { heteronormative social world }\end{array}$ \\
& $\begin{array}{l}\text { Lifelong problems forming social } \\
\text { connections }\end{array}$ \\
\hline Visibility and exclusion across social environments & $\begin{array}{l}\text { Being visible in a sea of couples } \\
\end{array}$ \\
\hline
\end{tabular}

to share day-to-day life with (emotional/intimate), while other men described their preferences for increased social contact with others (social), with some men referring to both types when reflecting on past and current experiences. Both forms of loneliness were accompanied by a broader narrative of social dislocation experienced in later life.

\section{Intimate loneliness: widowhood and bereavement}

Men from both groups, heterosexual and gay, had experienced bereavements from the death of an intimate partner and associated feelings of intimate loneliness. This theme was more prominent amongst heterosexual men due to the higher number of these men in the sample. Twenty-eight heterosexual men (living in urban and rural areas) were widowers and for most of these men there was considerable crossover in their experiences of grief, bereavement and loneliness. Men missed no longer being able to share everyday activities and conversations with their spouse/partner:

The hardest thing I found was not being able to talk it over with your wife. We were not just my wife, she was my friend as well. If we weren't sure about anything, she always backed me up, she was always very good that way. (M14, 84, heterosexual)

Following the death of a partner or spouse, older men find it difficult to maintain contact and companionship with others and experience a decrease in social relationships (Davidson, 2004; Bergland et al., 2016). This pattern is also reflected in our data as heterosexual men described their current lack of companionship and the social networks and routines their spouses had maintained:

...we had a lot of interests together, my wife and I. We'd go out together, I'd take her to the doctor, I'd take her to have her hairdo, we'd go for a coffee together, we'd go down and see my daughter because she's just five minutes down the road from here. Once a month it would be somebody's birthday, we used to go out for dinner at night, there was always things to do. That's all come to an end now. (M9, 78, heterosexual) 
Loneliness has long been framed as a dimension of widowhood and as part of the mourning process; it signals an emotionally charged transition to adjusting to living on one's own without the companionship of a long-term spouse/partner (Victor and Bennet, 2012; Bergland et al., 2016). Victor and Bennet (2012) identify absence as a prominent feature in older people's talk about loneliness and widowhood. Similarly, in our findings men identified the poignant and recurring absence of their spouse/partner in their daily and weekly routines. Like Victor and Bennet's (2012) participants, evenings were noted as an acutely difficult time when the absence was felt more intensely.

Other men discussed intimate loneliness in the context of yearning for a longterm partner - this was more tangible in gay men's reflections on loneliness and intimate relationships:

It's not just the physical thing of being physically alone, it's the emotional thing that is important ... I miss that opportunity for intimacy, for ordinary everyday affectionate gestures and acts and the lack of opportunity to do something spontaneous and enjoy it with someone else. (M21, 68, gay)

A long-term partner was perceived to bring everyday affection, consistent companionship and a sense of security as men grew older. For one gay man, however, the separation from, and subsequent death of his same-gender partner, had been a catalyst for his social life expanding:

My life could've become quite isolated when I split with my partner, and when he died, but it didn't. It actually expanded, if anything, because I went out there and joined things. I decided that was the way to go. For a person of my age at that time. (M73, 65, gay)

In contrast, other men (heterosexual and gay) situated loneliness in the context of having a social network they could turn to on a frequent basis, emphasising the security of having a consistent group of people around them in later life.

\section{Loneliness and living alone}

Loneliness was sometimes equated with being isolated from others, reinforced by living alone and desiring increased social contact with others. Some participants expressed resignation to living on their own in 'an empty house'. For mostly heterosexual men who were widowed, this reflected a sharp contrast from having lived long term with a spouse/partner:

I'm on my own a lot. Most evenings I'm on my own. It's quite difficult at times, but there you go. I'm quite resigned to it I think. (M61, 75, heterosexual)

A small group of gay men emphasised the advantages of living alone, such as the independence it brings, or identified this as a long-term living situation they had grown accustomed to: 
...I'm a very independent person. I quite like my own space and the freedom it gives me. But, the other side of the coin is there isn't that automatic companionship. Hence why I have to go out and look for it. (M3, 67, gay)

M3's comments suggest some ambivalence about living alone - it brings freedom and independence but equally the lack of companionship requires more active efforts to seek company outside the home. Another participant enjoyed living alone but worried about the future, particularly if needing care and support from others:

...living on my own, yes. I enjoy it, I don't think I could share it with anyone anymore, because I've become quite selfish about it. But, I have to think - that's okay right now, but if I become more dependent as time goes on, then that is a concern. (M21, 68, gay)

Similarly, from Yetter's (2010) qualitative study older men reported finding elements of living alone satisfying, including the freedoms it affords and opportunities for self-growth. For some men in our study, living alone is not synonymous with loneliness but brings with it the desire to connect more with others outside the home and to consider how to prepare for the future should their health and wellbeing decline.

\section{Social dislocation and disconnection in later life}

Across the interviews, men's talk on loneliness evoked a theme of social dislocation as they communicated a sense of social estrangement and separation from others and perceived a growing divide between themselves and wider society as they grew older. This thread ran across gay and heterosexual men's accounts. Some men used evocative metaphors such as 'being in a bottomless pit' to signify their sense of separation from others, while other men described the lived experience of loneliness as a 'cold ache' or a dark form that visited them, particularly at nighttime. M38 described feeling estranged from social and community life:

Estranged. You're estranged from what goes on out there. And the more you sit at home, with or without daytime TV, the more you're estranged from what's going on out there. You feel as though you're in a different world. (M38, 74, heterosexual)

M10 described loneliness as an associated perception that nobody wants to talk to him:

Loneliness to me means I'm entirely on my own, nobody is with me. To me, that's what loneliness is. And I feel that there is nobody around me, nobody sitting with me, there is nobody to talk to me. You know. I feel discarded, I feel left by human society and things like that. That's my feeling, how I feel. (M10, 74, heterosexual)

His comments also suggest a social divide between himself and wider society as he perceives himself as being 'discarded' and 'left by human society'. Reflecting on his isolation from others, M52 perceived himself as becoming increasingly 'irrelevant': 
You're just sat here, and in fact, last week I stayed in for, I think it was three days. I hardly spoke to a soul. I can text [name of friend], but in general, I hardly spoke to anyone. It's like, you're here, and you think to yourself, 'I could die here, and no one would take any notice.' You become irrelevant. It's like I said to you, 'My use here is done', unless... (M52, 66, gay)

The expression 'my use here is done' suggests a lack of purpose and redundancy in later life and points to a self-perceived decline in social status and value.

\section{Identifying triggers for loneliness: differences across social context and sexual identity}

Participants identified key life-changes and losses in their recent or current lives that had triggered experiences of loneliness, often associated with changes in their social circumstances and relationships. The most commonly discussed triggers mentioned by both gay and heterosexual men were lack of an intimate companion, overlapping with emotional loneliness, and feeling unsatisfied with levels of social contact within one's social network. Frequently reported triggers for both heterosexual and gay men included divorce or separation from long-term partners, extended periods of illness and poor health that impacted on levels of sociability, retirement from paid employment and the associated loss of social bonds formed within workplaces, and as discussed above, spousal/partner bereavements. The varying associations of these triggers with loneliness and social isolation have been discussed extensively elsewhere (e.g. Victor et al., 2000; Victor, 2013). Below we focus on two distinct facets of men's accounts, the first sub-theme being specific to gay men's social histories.

\section{Loneliness and isolation in a heteronormative social world}

Gay male participants discussed earlier and current experiences of both loneliness and isolation within social contexts that were more unique to their lifecourse and crossed over with gay identities. This included low levels of confidence in being 'out' to others as gay or same-gender attracted within their social networks, not having LGB groups and services in their vicinity, particularly in rural areas where such groups were limited or non-existent, and for one man, being diagnosed with HIV and feeling unable to discuss this with others due to the attached social stigma and shame.

Some gay men's accounts revolved around the metaphorical space of 'the closet' and not being out to others across their social, familial and collegial circles. In latemodern Western cultures, the closet metaphor has symbolised a space of shelter and protection from homosexual oppression; it represents what Sedgwick (1990: 71) describes as the 'defining structure for gay oppression' in the 20th century. Sedgwick (1990: 68) identifies the closet as a 'fundamental feature of social life' for many lesbian and gay people that has its foundations in the social and political divide between heterosexual and homosexual identities and relationships. One participant reflected on the social pressures of having to conceal his sexuality and the injustice of this being attached to gay men's lives: 
The great heterosexual world out there. I mean, they don't have to hide anything, and so they don't know how easy they've got it, really, compared with those who are isolated for some sort of reason, be they gay or they have some disadvantage. (M68, 85, gay)

Two men discussed how their earlier lives were 'compartmentalised' and the ways in which they maintained separate selves across different social circles and isolated themselves from others:

When you go back to the generation, I came out in my early twenties, at a time when there was much less social acceptance about being gay. Therefore, an awareness that my life was much more compartmentalised. I had a gay life, a family life, a work life and a neighbour life. To a certain extent that has continued, although it's become much more blurred. (M3, 67, gay)

Boundaries were maintained around their work connections, neighbourhood ties and family lives which remained separate from their 'gay lives'. For the participant above, these boundaries continued to exist but were now more permeable. As the oldest gay participant (85 years), one man discussed the imperative to maintain silence about his sexual desires during early adulthood in the 1950s and 1960s, and the heteronormative expectations to enter into marriage with a differentgender partner:

All my peers were getting married, they were all heterosexual, but I was the odd man out. I think the general assumption was, 'Poor old [name], he can't make it with the birds.' Birds meaning women, but little did they realise that [name] didn't want to make it with the birds. So, in those days, one had to keep it quiet. (M68, 85, gay)

For the majority of gay men current involvement in gay and LGB-specific local groups had helped ameliorate against social isolation and featured heavily in the descriptions of their social networks, as discussed by M68:

...via the social group [group name], to which I belong, I can readily see my friends. Whereas if I did not belong to something like that, then there would be a degree of isolation, there ... I make a point, and I enjoy doing it, of going to [group] very regularly.

Another participant described the isolation he sometimes experienced in 'straight' male environments such as his local pub:

I mean, to a degree. If I do go over to the local pub, which I do when the Six Nations Rugby is on, then yes, there are several people in there who are rugby fans, but there are ... I think there are about two people in there I know to be gay. So yes, you do feel a bit out on a limb there. (M78, 68, gay) 
His comments reiterate the social value of gay men's, and LGB, spaces in which older gay men feel less 'out on a limb'. Participants continually emphasised the importance of having access to LGB-focused groups and social spaces in their local area beyond bars and nightclubs:

It's not easy to meet new people of the same sexual orientation. When you're younger, you go along to the bars, to the nightclubs. But, to go there as somebody who was in his fifties, heading towards 60 , it's not the place to be, really. So, that's why I thought, 'No, the better option is to join things', and that's what I did. In the city, ... we've got a gay orchestra, we've got a gay choir, there's a gay football team $\ldots$ There are all kinds of things. (M73, 65 , gay)

This was distinct from heterosexual men who emphasised the significance of participating in a wide range of social groups, including clubs and societies, but not groups affiliated around social and sexual identities.

\section{Lifelong problems forming social connections}

Negative life experiences in earlier years had left imprints on a small group of men's capacities to form and enjoy friendships with others or to get involved in groups in their locality. Across both groups, gay and heterosexual, men discussed lifelong problems forming friendships and social bonds rather than identifying specific life changes triggering loneliness. Some participants described themselves as 'lone wolves' or 'social introverts' from childhood onwards and had encountered difficulties forming friendships:

Too much contact with people, I get tired. Some people are extroverts, they thrive on social contact. I need a rest from people to re-energise, do you see what I mean? (M51, 68, heterosexual)

Within these accounts, men tended to locate their experiences of loneliness as an individual characteristic rather than a reflection of their social circumstances or life-stories. This was despite some men's experiences of being a 'lone wolf overlapping with earlier childhood (and often traumatic) experiences, e.g. being in foster care or experiencing extended periods of hospitalisation due to chronic illness. This resonates with other qualitative explorations of how traumatic or distressing life-events in childhood can impact on older people's capabilities in later life (Tiilikainen and Seppänen, 2017); in the case of our findings, impacting on men's social capabilities in forming new social bonds and friendships.

\section{Visibility and exclusion across social environments}

The recruitment strategy for our study involved reaching out to established groups, including groups run by community organisations, social clubs and older people's services. Given this, it is no surprise that experiences of loneliness did not inhibit the majority of men from participating in group activities. Most men reported routine participation in a range of groups including civic and interest-based groups (e.g. University of the Third Age, Probus, Men's Sheds and Age UK groups) and activity-based groups centred on shared interests (e.g. walking clubs, art and 
reading groups, gardening clubs). However, group participation generated its own cluster of concerns and social anxieties, centred around potential exclusion and visibility in group settings. Men from both groups (heterosexual and gay) expressed concerns about visibility and potential exclusion but in differing ways.

\section{Being visible in a sea of couples}

Heterosexual men conveyed a heightened consciousness of their individual status as single or widowed and the social connotations that accompanied this of being lonesome and therefore socially undesirable. This was discussed in relation to group participation and men's anticipated exclusion because of their status as older, single and/or widowed in these settings. One man described feeling lonely in group events and parties:

...I, sort of, look round and see other people in groups or in pairs or what, then something, sort of, gets me as, 'Ooh, I'm here. I'm all alone.' And then I, sort of, experience a feeling of, 'There's nobody there. I'm completely on my own. Always have been and always will be.' (M8, 67, heterosexual)

Several participants discussed their anxieties about being visible as older, single or widowed men in group settings. Some described feeling excluded in group activities full of (different gender) couples and how attending on one's own could sometimes influence interactions with others in the group. M89 described himself as a 'spare part' during a social event in a rural pub near his residence:

So they'll all have their wives, so a couple of guys I normally sit by - or can sit by there was a [name of social club] meeting last night ... They'll have their wives with them, so they'll sit in the wives' friends' groups. The wives are in a wheel, so the blokes can't just hideaway - they can't sit with their mates, they've got to go and sit with their wives who sit with their mates, you see. So I'd just be a spare part, so I don't go. (M89, 81, heterosexual)

In addition to concerns voiced about feeling excluded from group activities and conversations, heterosexual men expressed anxieties about the display of friendly affection to other men's female partners and the ways in which these acts could be misinterpreted. Some men were worried about actions of physical affection being misread as attracted to or romantically interested in women in relationships, e.g. greeting another man's spouse with a hug. One participant discussed his social anxieties:

And they're men and women together. They're man and wife, or they are sisters, and all this lot. I'm not being funny; I look on it that men sometimes look on you as - what is the word? - a predator on women. Do you know what I mean? Because I'm alone. 'Why are you here? Where is your wife?' So I tell everyone I'm a widower. But you're an outcast. (M2, 70, heterosexual)

For M2, telling people he was a widower rather than a single man helped justify his solo status to others, however, he still perceived himself as an outcast when amongst 
couples. Sandberg's (2018) work on the importance of touch in older men's accounts of sexual intimacy points to an alternative, more empowering discourse of sexual relationships that moves beyond dominant understanding of (hetero)sexual activity in later life as being phallo-centric and primarily associated with impotence and decline. In our study, intimate touch holds different connotations as single, heterosexual men were hyper-aware of how touch has the potential to be misread as romantic attraction and the social anxieties this evoked in group situations along with the potential shame attached to being single in later life.

\section{Invisibility within gay social settings}

As discussed above, the majority of gay men stressed the importance of participating in gay men's and LGB groups as identity-affirming spaces, with particular emphasis on seeking opportunities to connect with gay men of different generations. However, participants encountered a number of social barriers to participating in LGB social spaces and settings. Gay men frequently described themselves as invisible in youth-centred pubs, clubs and commercial events where they felt ignored or misperceived as a 'dirty old man':

I'm a minority within a minority because, first of all, I'm gay - which is a minority group - but secondly, I'm old. It means I'm a minority amongst the gay people because a lot of young people don't want old men around. Can't be bothered with old men. (M86, 74, gay)

Ageism within LGB social spaces emerged as a problem for older gay men seeking social and romantic connections with other men, and made dating and seeking sexual partners difficult. Three men discussed the impact of being an older man on meeting other men, especially a potential long-term partner, in gay social spaces. One man worried about how he was being perceived as older and gay within gay clubs:

That it's a youth culture these days, and particularly in the gay society. And if you're older than a certain age, you're just thought of as an old man, and maybe sometimes a dirty old man, at that. (M63, 67, gay)

The youth-centred culture of what he terms as 'gay society', and associated judgements, made the prospect of entering a fulfilling relationship with a younger man difficult:

It is pointless my going to a [gay] club, or a discotheque, or anything. I am, you know, just ... the expression that we use is invisible, and that is it. You stand there, and you might as well not be there. You are not even seen. (M72, 68, gay)

Gay men's spaces, specifically commercial spaces targeting gay men, such as bars and clubs, were experienced as ageist and marginalising environments where gay men felt ignored at best or misperceived as predatory at worst. Simpson (2013) argues that middle-aged and older men can experience the ever-present 'gay gaze' in gay bars and clubs as affirming (i.e. signalling sexual desire and interest) 
or as a source of alienation as older men are perceived to be 'too old' to occupy these spaces. Single gay men in our study experienced the latter perceptions of exclusion and invisibility in gay venues, which impeded attempts to connect with men from younger generations and for some men complicated their preferences for younger sexual/romantic partners.

\section{Discussion}

Our aims in this investigation of older men's experiences of loneliness were to examine how men who were single and/or living alone talk about loneliness, isolation and social dislocation, and to identify how differences across sexual identity and social context shape their experiences and observations. Akin with other qualitative studies (Bergland et al., 2016; Leontowitsch et al., 2019), older men's accounts convey heterogeneity in how they experience and describe loneliness, coupled with their experiences of living alone, and complexity in the different life-events that trigger loneliness, past and present.

Across the literature on loneliness and ageing, very little attention has been given to the intersection of ageing, sexuality and masculinities in older men's accounts. Our findings bring gay men's experiences to the fore in two ways. First, the findings show how gay men's experiences of loneliness are tinted by having to negotiate heteronormative social environments during contemporary life and earlier decades. Social expectations on maintaining normative social and intimate relationships generate periods of social isolation, exemplified by the concealment of gay identities and same-gender desires, and the maintenance of boundaries across social networks. Over their lifetime these men have occupied and lived across social environments in which they have had limited permission to safely discuss their sexual identity, relationships and attractions with others. While these opportunities may have expanded in parallel with increased recognition of equal civil and legal rights for LGB citizens, popular social spaces, such as the village pub, continue to be experienced as heteronormative spaces.

Second, the findings reiterate the significance of gay and LGB groups and social spaces as environments of belonging while bringing to attention the complexities of identifying as older and gay in some of these spaces (e.g. bars and clubs). Within these spaces representations of youthful manhood are privileged over other masculinities; this interrupts older gay men's attempts to forge social and intimate ties with men from younger generations and bolsters age-related barriers to creating 'chosen families' across generations. The availability of spaces where gay men can connect with other gay men, through venues or services, is limited and even more so for men living outside major urban enclaves, reflecting a form of sociosexual isolation. These spaces do not always bring the promise of inclusion, support and validation (and in some instances potential romance) anticipated.

We also seek to highlight the similarities in findings across heterosexual and gay men's accounts. Most notable is the emphasis both groups of men give to perceptions of social dislocation and separation from others; these responses partly resonate with discussions of existential loneliness (Ettema et al., 2010; Bolmsjö et al., 2018). Ettema et al. (2010) identify three dimensions to existential loneliness: (a) as a condition - a perceived state of social separation from others; (b) as an 
experience - the associated feelings of emptiness and nothingness associated with this state, and (c) as a process and source of personal growth. Within men's accounts, there are glimmers of the first two dimensions. This is accompanied by an intense awareness of social estrangement as men described their perception of increasing social voids between themselves and others in their social networks and, in some instances, wider community relations. There are also occasional examples of the third dimension, e.g. the growth of one individual's social network following the death of his partner, highlighting how positive changes to an individual's social wellbeing can emerge from major disruptions to an individual's intimate and social relationships.

Through an ageing lens, the majority of men (heterosexual and gay) convey an acute awareness of a shrinking social world in parallel with a sense of wider social dislocation and of diminished social worth. At first glance this can be read as a growing social void experienced by older men as their interactions across social settings such as the workplace and their social contact with others decreases. A further reading of these accounts suggests that these men are reflexively aware of changes in their levels of social participation and their increasing separation from others. This reflexive position enables men to re-assess their current levels of social separation and for engaging in the third dimension of transformation identified by Ettema et al. (2010) by seeking to enhance their social connections through group involvement. Our findings signify a lived experience of 'othering' in old age where men perceive themselves as separated and detached from others based on the 'chronological otherness of old age' (Higgs and Gilleard, 2020) and their gendered status as subordinate masculinities (Slevin and Linneman, 2010).

Bennett (2007) argues that for older men later life is associated with a loss of hegemonic qualities attached to masculinities, such as autonomy, physical strength and mental resiliency. For men in our study, older age is also associated with a perceived loss of social recognition and social worth. In relation to gay men's lives, the intersection between old age, sexual identity and the performance of masculinities within gay subcultures generates additional barriers to connecting with other gay men. Another form of 'othering' is occurring within these social settings (Simpson, 2013). Oswald and Roulston (2018) argue that gay men experience enduring losses across the lifecourse, including the loss of social and emotional connections. These losses stem from the stigmatisation of gay identities across social, cultural and legal spheres. Arguably, older gay men may be more accustomed to the loss of social status and social connections that derives from living in heteronormative environments, and the extent of these losses will hinge on other intersecting factors such as levels of socio-economic status and class. A key question for future research is whether older gay men have developed unique coping practices that enable them to cope with and bounce back from this loss of social status in later life that heterosexual men have not developed or needed to develop until older age.

Despite these losses, men in our study retain hegemonic attributes of autonomy and independence and across the findings there are examples of men seeking to increase their levels of social participation by accessing groups and services in their locality. While loneliness had been a problem for many participants, they were not immobilised from seeking to enhance their social connections. These 
experiences reveal a distinctive set of social anxieties where differences across sexual identity and social context are more palpable. To apply the terminology of Franklin et al. (2019), there are a range of social environments that appeal to older men who are single or living alone as potential sites of 'belongingness', but these environments also generate barriers to participation. For both groups there are dominant images within their descriptions of social environments that signify subordinate masculinities - for heterosexual men images of single, older men as lonesome amongst couples, socially undesirable and a potential source of sexual threat to other men's spouses, and for gay men invisibility as older men in youth-centred spaces coupled with misperceptions of being 'dirty, old men'. Service providers running group-based interventions for older men would benefit from an enhanced understanding of the social anxieties attached to group participation and associated barriers to be able to plan and design collective activities that validate the participation of men who are single and/or living alone.

\section{Limitations to the research design}

There are some limitations to this study. The sample is non-representative which limits the transferability of findings to other contexts. Participants were selfselecting, which did not inhibit men from sharing moments of loneliness but because of this we were unlikely to interview men experiencing high degrees of social isolation and, as a result, less likely to be involved with groups and services through which we recruited. While our sample has some heterogenous features across residential context (urban and rural locations) and sexual identity, there are notable gaps in the limited number of men from black and ethnic minority backgrounds and the lack of men identifying as bisexual. As part of our recruitment strategy we approached services and networks aimed at these specific groups, e.g. groups targeting both gay and bisexual men. However, this strategy was not successful, and it may be that members of these missing groups are not accessing the services we approached, despite their inclusion in the service's brief. More concerted efforts are needed to ensure these perspectives on loneliness and social connections are amplified.

\section{Concluding comments}

At the heart of this paper has been a focus on loneliness as a social phenomenon in the UK that is prominent within discussions of ageing, single status and living alone. In this paper, we have examined sources of commonality and difference across gay and heterosexual men's accounts as older men who are single and/or living alone. The social bonds of older men from both these groups is an under-served topic within studies of ageing and loneliness. Men's awareness of their sense of social dislocation and estrangement from others permeates accounts from both groups while not hindering older men from accessing local groups and group-based activities. An additional area for future research is an in-depth examination of how older men from different sexual identities do 'kinship' and form new social bonds in naturally occurring social environments that are not facilitated by an organisation or service, inclusive of online environments. Finally, the study's findings 
convey the importance of enhancing men's social connections in later life and counteracting negative discourse of social dislocation and estrangement expressed by men. For service providers running social interventions for older men, a concerted focus is needed on facilitating men's involvement in roles and responsibilities that reinforce messages of contribution and validation in a social world where older men are cognisant of their estrangement from others.

Acknowledgements. Our sincere appreciation to the men who took part in the study and our thanks to the reviewers for their helpful comments in refining this paper.

Financial support. This work was supported by a research grant from the National Institute for Health Research School for Social Care Research, 2016-19 (reference CO88/CM/UBDA-P110).

Ethical standards. Ethical approval was received from the NHS England Social Care Research Ethics Committee (Ref. 17/IEC08/0004).

\section{References}

Almack K (2019) 'I didn't come out to back in the closet': ageing and end-of-life care for older LGBT people. In King A, Almack K, Suen Y-T and Westwood S (eds), Older Lesbian, Gay, Bisexual and Trans People: Minding the Knowledge Gaps. Abingdon, UK: Routledge, pp. 158-171.

Beach B and Bamford S (2013) Isolation: The Emerging Crisis for Older Men. London: Independent Age. Available at https://www.independentage.org/policy-research/research-reports/isolation-emerging-crisisfor-older-men.

Bennett KM (2007) 'No sissy stuff: towards a theory of masculinity and emotional expression in older widowed men. Journal of Aging Studies 21, 347-356.

Bennett KC and Thompson NL (2008) Accelerated aging and male homosexuality: Australian evidence in a continuing debate. Journal of Homosexuality 20, 65-75.

Bennett KM, Hughes GM and Smith PT (2003) 'I think a woman can take it': widowed men's views and experiences of gender differences in bereavement. Ageing International 28, 408-424.

Bergland AMG, Tveit B and Gonzalez MT (2016) Experiences of older men living alone: a qualitative study. Issues in Mental Health Nursing 37, 113-120.

Bolmsjö I, Tengland P-A and Rämgård M (2018) Existential loneliness: an attempt at an analysis of the concept and the phenomenon. Nursing Ethics 26, 1310-1325.

Braun V and Clarke V (2006) Using thematic analysis in psychology. Qualitative Research in Psychology 3, 77-101.

Brennan-Ing M, Seidel L, Larson B and Karpiak SE (2014) Social care networks and older LGBT adults: challenges for the future. Journal of Homosexuality 61, 21-52.

Buffel T, Rémillard-Boilard S and Phillipson C (2015) Social Isolation Among Older People in Urban Areas: A Review of the Literature for the Ambition for Ageing Programme in Greater Manchester. Manchester, UK: Manchester Institute for Collaborative Research on Ageing. Available at http://hummedia. manchester.ac.uk/institutes/micra/Handbooks/Buffel\%20Tine\%20-\%20A5\%20Brochure\%20-\%20Social\%20 Isolation.pdf.

Byles J, Vo K, Thomas L, Mackenzie L and Kendig H (2016) Partner status and mental and physical health of independently living men aged 70 years and older. Australasian Journal on Ageing 35, 143-146.

Cacioppo S, Grippo AJ, London S, Goossens L and Cacioppo JT (2015) Loneliness: clinical import and interventions. Perspectives on Psychological Science 10, 238-249.

Calasanti T (2004) Feminist gerontology and old men. Journals of Gerontology: Psychological Sciences and Social Sciences 59B, S305-S314.

Connell RW (1995) Masculinities. Cambridge: Polity Press.

Connell RW and Messerschmidt JW (2005) Hegemonic masculinity: rethinking the concept. Gender \& Society 19, 829-859.

Crenshaw K (1991) Mapping the margins: intersectionality, identity politics, and violence against women of color. Stanford Law Review 43, 1241-1299. 
Croghan CF, Moone RP and Olson AM (2014) Friends, family, and caregiving among midlife and older lesbian, gay, bisexual, and transgender adults. Journal of Homosexuality 61, 79-102.

Davidson K (2004) 'Why can't a man be more like a woman?' Marital status and social networking of older men. Journal of Men's Studies 13, 25-43.

Davidson K, Daly T and Arber S (2003) Older men, social integration and organisational activities. Social Policy and Society 22, 81-89.

De Jong-Gierveld J (1987) Developing and testing a model of loneliness. Journal of Personality and Social Psychology 53, 119-128.

De Jong Gierveld J and van Tilburg T (2006) A 6-item scale for overall, emotional, and social loneliness: confirmatory tests on survey data. Research on Aging 28, 582-598.

Durcan D and Bell R (2015) Local Action on Health Inequalities: Reducing Social Isolation Across the Lifecourse. London: Public Health England and UCL Institute of Health Equity. Available at https:// assets.publishing.service.gov.uk/government/uploads/system/uploads/attachment_data/file/461120/3a_ Social_isolation-Full-revised.pdf.

Dykstra PA and Fokkema T (2007) Social and emotional loneliness among divorced and married men and women: comparing the deficit and cognitive perspectives. Basic and Applied Social Psychology 29, 1-12.

Emlet CA, Brennan DJ, Brennenstuhl S, Rueda S, Hart TA, Rourke SB and the OHTN Cohort Study Team (2013) Protective and risk factors associated with stigma in a population of older adults living with HIV in Ontario, Canada. AIDS Care 25, 1330-1339.

Ettema EJ, Derksen LD and van Leeuwen E (2010) Existential loneliness and end-of-life care: a systematic review. Theoretical Medicine and Bioethics 31, 141-169.

Fish J and Weis C (2019) All the lonely people, where do they all belong? An interpretive synthesis of loneliness and social support in older lesbian, gay and bisexual communities. Quality in Ageing and Older Adults 20, 130-142.

Fokkema T and Kuyper L (2009) The relation between social embeddedness and loneliness among older lesbian, gay, and bisexual adults in the Netherlands. Archives of Sexual Behavior 38, 264-275.

Franklin A, Barbosa Neves B, Hookway N, Patulny R, Tranter B and Jaworski K (2019) Towards an understanding of loneliness among Australian men: gender cultures, embodied expression and the social bases of belonging. Journal of Sociology 55, 124-143.

Gale N, Heath G, Cameron E, Rashid S and Redwood S (2013) Using the framework method for the analysis of qualitative data in multi-disciplinary health research. BMC Medical Research Methodology 13, 117.

Gale C, Westbury L and Cooper C (2018) Social isolation and loneliness as risk factors for the progression of frailty: the English Longitudinal Study of Ageing. Age and Ageing 47, 392-397.

Green M (2016) Do the companionship and community networks of older LGBT adults compensate for weaker kinship networks? Quality in Ageing and Older Adults 17, 36-49.

Grov C, Golub SA, Parsons JT, Brennan M and Karpiak SE (2010) Loneliness and HIV-related stigma explain depression among older HIV-positive adults. AIDS Care 22, 630-639.

Guasp A (2011) Lesbian, Gay and Bisexual People in Later Life. London: Stonewall. Available at https:// www.stonewall.org.uk/sites/default/files/LGB_people_in_Later_Life_2011_.pdf.

Heaphy B, Yip AKT and Thompson D (2004) Ageing in a non-heterosexual context. Ageing \& Society 24, 881-902.

Hearn J (1995) Imaging the ageing of men. In Featherstone M and Wernick A (eds), Images of Aging: Cultural Representations of Later Life. London: Routledge, pp. 97-115.

Higgins A, Sharek D, McCann E, Sheeran F, Glacken M, Breen M and McCarron M (2011) Visible Lives: Identifying the Experiences and Needs of Older Lesbian, Gay Bisexual and Transgender People in Ireland. Dublin: Gay and Lesbian Equality Network.

Higgs P and Gilleard C (2020) The ideology of ageism versus the social imaginary of the fourth age: two differing approaches to the negative contexts of old age. Ageing \& Society 40, 1617-1630.

HM Government (2018) A Connected Society: A Strategy for Tackling Loneliness - Laying the Foundations for Change. London: Department for Digital, Culture, Media and Sport. Available at https://assets. publishing.service.gov.uk/government/uploads/system/uploads/attachment_data/file/750909/6.4882_DCMS_ Loneliness_Strategy_web_Update.pdf.

HM Government (2020) Loneliness Annual Report: The First Year. London: Department for Digital, Culture, Media and Sport. Available at https:/www.gov.uk/government/publications/loneliness-annualreport-the-first-year. 
Hughes M (2016) Loneliness and social support among lesbian, gay, bisexual, transgender and intersex people aged 50 and over. Ageing \& Society 36, 1961-1981.

Hughes ME, Waite LJ, Hawkley LC and Cacioppo JT (2004) A short scale for measuring loneliness in large surveys: results from two population-based studies. Research on Aging 26, 655-672.

Hulko W (2016) LGBT* individuals and dementia: an intersectional approach. In Westwood S and Price E (eds), Lesbian, Gay, Bisexual and Trans ${ }^{*}$ Individuals Living with Dementia: Concepts, Practice and Rights. New York, NY: Routledge, pp. 35-50.

Isherwood LM, King DS and Luszcz MA (2012) A longitudinal analysis of social engagement in late-life widowhood. International Journal of Aging \& Human Development 74, 211-229.

Jones J and Pugh S (2005) Ageing gay men: lessons from the sociology of embodiment. Men and Masculinities 7, 248-260.

Jopling K (2015) Promising Approaches to Reducing Loneliness and Isolation in Later Life. London: Campaign to End Loneliness and Age UK. Available at https:/www.campaigntoendloneliness.org/wpcontent/uploads/Promising-approaches-to-reducing-loneliness-and-isolation-in-later-life.pdf.

Jylhä M and Saarenheimo M (2010) Loneliness and ageing: comparative perspectives. In Dannefer D and Phillipson C (eds), The Sage Handbook of Social Gerontology. London: Sage, pp. 317-329.

Kim HJ and Fredriksen-Goldsen KI (2016) Living arrangement and loneliness among lesbian, gay, and bisexual older adults. The Gerontologist 56, 548-558.

King A, Almack K and Jones RL (2019) Introduction: Intersections of ageing, gender and sexualities. In King A, Almack K and Jones RL (eds), Intersections of Ageing, Gender and Sexualities: Multidisciplinary International Perspectives. Bristol, UK: Policy Press, pp. 1-8.

Kitzinger C (2005) Heternormativity in action: reproducing the heterosexual nuclear family in after-hours medical calls. Social Problems 52, 477-498.

Leontowitsch M, Fooken I and Oswald F (2019) The role of empowerment and agency in the lives of older men living alone. European Journal for Research on the Education and Learning of Adults 10, 231-246.

Lyons A, Pitts MK and Grierson J (2012) Growing old as a gay man: psychosocial wellbeing of a sexual minority. Research on Ageing 35, 275-295.

Markson EW (1975) Editor's note: Disengagement theory revisited. International Journal of Aging and Human Development 6, 183-186.

Meyer IH (2003) Prejudice, social stress, and mental health in lesbian, gay, and bisexual populations: conceptual issues and research evidence. Psychological Bulletin 129, 674-697.

Mijuskovic BL (1979) Loneliness in Philosophy, Psychology and Literature. Assen, The Netherlands: Van Gorum.

Milligan C, Payne S, Bingley A and Cockshott Z (2015) Place and wellbeing: shedding light on activity interventions for older men. Ageing \& Society 35, 124-149.

Office for National Statistics (ONS) (2018) Loneliness - What Characteristics and Circumstances Are Associated with Feeling Lonely? Available at https://www.ons.gov.uk/peoplepopulationandcommunity/ wellbeing/articles/lonelinesswhatcharacteristicsandcircumstancesareassociatedwithfeelinglonely/201804-10.

Office for National Statistics (ONS) (2019) The Cost of Living Alone. Available at https://www.ons.gov.uk/ peoplepopulationandcommunity/birthsdeathsandmarriages/families/articles/thecostoflivingalone/201904-04.

Oswald A and Roulston K (2018) Complex intimacy: theorizing older gay men's social lives. Journal of Homosexuality 67, 223-243.

Pereira H, Serrano JP, de Vries B, Esgalhado G, Afonso RM and Monteiro S (2017) Aging perceptions in older gay and bisexual men in Portugal: a qualitative study. International Journal of Aging and Human Development 87, 5-32.

Perlman D and Peplau LA (1981) Towards a social psychology of loneliness. In Duck SW and Gilmour R (eds), Personal Relationships in Disorder. London: Academic Press, pp. 31-56.

Sandberg LJ (2018) Closer to touch: sexuality, embodiment and masculinity in older men's lives. In Katz S (ed.), Ageing in Everyday Life: Materialities and Embodiments. Bristol, UK: Policy Press, pp. 129-144.

Sedgwick EK (1990) Epistemology of the Closet. Berkeley, CA: University of California Press.

Simpson P (2012) Perils, precariousness and pleasures: middle-aged gay men negotiating urban 'heterospaces'. Sociological Research Online 17, 124-133. 
Simpson P (2013) Alienation, ambivalence, agency: middle-aged gay men and ageism in Manchester's gay village. Sexualities 16, 283-299.

Slevin KF and Linneman TJ (2010) Old gay men's bodies and masculinities. Men and Masculinities 12, 483-507.

Thompson EH (2006) Images of old men's masculinity: still a man? Sex Roles 55, 633-648.

Tiilikainen E and Seppänen M (2017) Lost and unfulfilled relationships behind emotional loneliness in old age. Ageing \& Society 37, 1068-1088.

Victor C (2013) Loneliness amongst older people: prevalence rates, risk factors and trajectories of change. European Journal of Public Health 23, supplement 1, 115.

Victor KM and Bennet C (2012) 'He wasn't in that chair': what loneliness means to widowed older people. International Journal of Ageing and Later Life 7, 33-52.

Victor C, Scambler S, Bond J and Bowling A (2000) Being alone in later life: loneliness, social isolation and living alone. Reviews in Clinical Gerontology 10, 407-417.

Victor CR, Scambler SJ and Marstton L (2006) Older people's experience of loneliness in the UK - does gender matter? Social Policy \& Society 5, 27-38.

Vozikaki M, Papadaki A, Linardakis M and Philalithis A (2018) Social isolation and wellbeing among older adults in Europe. Archives of Hellenic Medicine 35, 506-519.

Weiss R (1973) Loneliness: The Experience of Emotional and Social Isolation. Cambridge, MA: MIT Press.

Weston K (1997) Families We Choose: Lesbians, Gays, Kinship. New York, NY: Columbia University Press.

Willis P, Raithby M and Maegusuku-Hewett T (2018) 'It's a nice country but it's not mine': exploring the meanings attached to home, rurality and place for older lesbian, gay and bisexual adults. Health and Social Care in the Community 26, 908-916.

Yetter LS (2010) The experience of older men living alone. Geriatric Nursing 31, 412-418.

Cite this article: Willis P, Vickery A, Jessiman T (2022). Loneliness, social dislocation and invisibility experienced by older men who are single or living alone: accounting for differences across sexual identity and social context. Ageing \& Society 42, 409-431. https://doi.org/10.1017/S0144686X20000914 